\title{
Surveillance for Opioid Overdose in the Veterans Health Administration, 2004-2014
}

\author{
Carla Winston* and Mark Holodniy \\ U.S. Department of Veterans Affairs, Palo Alto, CA, USA
}

\section{Objective}

To examine inpatient admissions for opioid overdose among U.S. Veterans using national-level surveillance data.

\section{Introduction}

Drug poisoning, or overdose, is an epidemic problem in the United States ${ }^{1,2}$. In keeping with national trends, a recent study combining U.S. Veterans Health Administration (VHA) data with the National Death Index showed increases in opioid overdose mortality from 2001 to $2009^{3}$. One of the challenges in monitoring the overdose epidemic is that collecting cohort data to analyze overdose rates can be laborintensive. Moreover, analysts are often unable to collect real-time data on overdose events. To explore solutions to these challenges, we examined opioid overdose by using Veteran healthcare data already being collected for syndromic surveillance.

\section{Methods}

We analyzed data from the VHA Electronic Surveillance System for Early Notification of Community-based Epidemics (ESSENCE) platform for January 2004 through June 2014. After evaluating both inpatient and outpatient data, we restricted the analysis to admissions with a principal diagnosis of opioid poisoning in order to reflect severe acute events. We included any admissions with a principal diagnosis of 965.00 (opium alkaloids unspecified), 965.01 (heroin), 965.02 (methadone), or 965.09 (other opiates and related narcotics). We calculated opioid poisoning rates per 1,000 inpatient admissions by age group and U.S. Census region.

\section{Results}

A total of 6,317 admissions with a principal diagnosis of opioid poisoning were reported out of 5,459,815 admissions. Death was the final outcome for $64(1.0 \%)$ opioid admissions. Rates of opioid poisoning were highest among younger Veterans, and lowest among Veterans age 65 years and older (Table). Trends over time showed increases for all except $45-54$ year olds $(\mathrm{p}=0.16$; $\mathrm{p}<=0.02$ for all other groups), for whom the opioid poisoning rate was initially highest during the study period. Overdose rates were highest in the Western United States, where trends were stable over time $(\mathrm{p}=0.46)$ compared with increases in other regions $(\mathrm{p}<0.01)$. Total rates appear to have peaked in 2010 and subsequently plateaued (Figure).

\section{Conclusions}

We found that surveillance data could effectively be mined for evaluating opioid poisoning among Veterans. Although we focused on principal diagnosis, trends in all opioid poisoning ICD-9 codes and supplemental E codes indicating causes of injuries paralleled our current findings. As a proof of concept similar to assessing suicidal ideation using telephone triage data ${ }^{4}$, we have used routine VHA surveillance data as a timely way to assess the opioid epidemic among Veterans. VHA is committed to reducing opioid morbidity through treatment and education ${ }^{5}$.
Opioid Poisoning Admissions, ICD-9 Codes 965.00-965.09, by Age

\begin{tabular}{|c|c|c|c|}
\hline Age Category & $\begin{array}{c}\text { Opioid } \\
\text { Admissions }\end{array}$ & $\begin{array}{c}\text { Total } \\
\text { Admissions }\end{array}$ & $\begin{array}{c}\text { Average Annual Rate per 1,000 } \\
\text { Admissions }\end{array}$ \\
\hline $\begin{array}{c}\text { Less than 35 years } \\
\text { old }\end{array}$ & 469 & 194,192 & 2.27 \\
\hline 35-44 years & 468 & 273,526 & 1.72 \\
\hline 45-54 years & 1,679 & 876,579 & 1.91 \\
\hline 55-64 years & 2,507 & $1,787,170$ & 1.39 \\
\hline 65-74 years & 799 & $1,086,959$ & 0.72 \\
\hline 75 years and older & 395 & $1,241,389$ & 0.32 \\
\hline
\end{tabular}

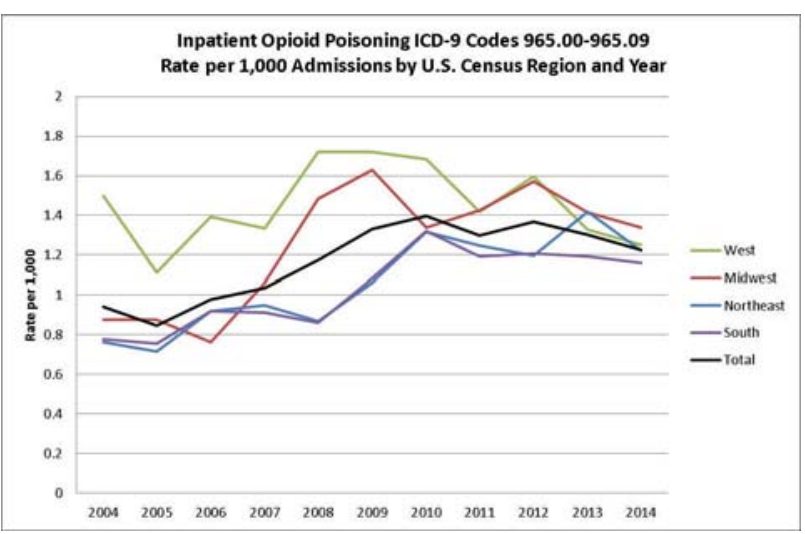

\section{Keywords}

opioids; overdose; trends; regional variation

\section{Acknowledgments}

The findings in this report are those of the authors and do not reflect the official position of the U.S. Department of Veterans Affairs.

\section{References}

1. Office of National Drug Control Policy. White House Summit on the Opioid Epidemic. http://www.whitehouse.gov/blog/2014/06/19/ white-house-summit-opioid-epidemic Accessed August 14, 2014.

2. Centers for Disease Control and Prevention. Vital signs: overdoses of prescription opioid pain relievers-United States, 1999-2008. MMWR. 2011 Nov 4;60(43):1487-1492.

3. Bohnert AS, Ilgen MA, Trafton JA, et al. Trends and regional variation in opioid overdose mortality among Veterans Health Administration patients, fiscal year 2001 to 2009. Clin J Pain. 2014 Jul 1; 30(7):605612.

4. Ludwig A, Lucero-Obusan C, Schirmer P, Holodniy M. Characteristics of Veterans accessing the Veterans Affairs telephone triage who have depression or suicidal ideation: opportunities for intervention. Online J Public Health Inform. 2013; 5(1): e136.

5. Veterans Health Administration. Implementation of opioid overdose education and naloxone distribution to reduce risk of opioid-related death. Under Secretary for Health's Information Letter, IL 10-2014. May 13, 2014.

\section{*Carla Winston}

E-mail: carla.winston@va.gov 